AGH DRILLING, OIL, GAS • Vol. 33 • No. 2 • 2016

http://dx.doi.org/10.7494/drill.2016.33.2.259

\author{
Jann Rune Ursin*
}

\title{
GAS-CONDENSATE BANKING AND WELL DELIVERABILITY. A COMPARATIVE STUDY USING ANALYTICAL- AND NUMERICAL MODELS
}

\section{INTRODUCTION}

Gas-condensate reservoirs represent an important part of hydrocarbon reserves. Unfortunately, production of these resources involves great challenges related to thermodynamic aspects of their fluids and dynamical behavior in the reservoir. Understanding and modeling the fluid phase behavior and flow in the reservoir are tough challenges.

Production from gas-condensate reservoirs are characterized by liquid condensation in the reservoir as the pressure declines below the dew point pressure $[1,2]$. The first drops of condensate oil will form in the close vicinity of the wellbore, where the reservoir pressure reaches its lowest value. As more gas is produced, reservoir pressure will continue to decrease and the volume where condensate oil is formed will gradually grow and expand radially into the reservoir. As this process continues more and more liquid is stored in the pore space and in some part act as a hinderance to the free flow of gas. Eventually the saturation of condensate oil will reach its level of critical saturation where the oil becomes continuous in the pore space and then star to flow. When this happens, reservoir production is characterized by two-phase flow and the draw down pressure will increase considerably, leading to a drop in bottom hole pressure (in the case of constant surface gas production).

The problem of gas-condensate banking is therefore twofold as the heavy ends (long chained hydrocarbons) being the most valuable part of the originally gas in place, are dropping out of the gas and considered, to a great part, lost production. Secondly, when the condensate oil starts to flow in the reservoir, an increased draw down and

* University of Stavanger, 4036 Stavanger, Norway 
reduce well deliverability will eventually cause a premature shut down of well production due to minimum bottom hole pressure restrictions. As many gas-condensate reservoirs are produced under a pre-negotiated gas sales agreement, unexpected draw down and reduced well deliverability due to liquid dropout could endanger any sales contract.

The effect of condensate banking on well deliverability is an active research field of great interest and activity among many researchers as well as among reservoir engineers in the petroleum industry. The buildup of the condensate bank in the reservoir and its consequences on well productivity have been extensively studied in literature by various authors [3-6].

Productivity loss due to condensate build up can in some cases be striking [7], where decline-factors as high as 30 are observed. Several other examples of severe productivity decline has previously been presented by other authors $[8,9]$. Well deliverability can even be a problem in very lean gascondensate reservoirs, where maximum liquid dropout as low as $1 \%$ can cause reduction in productivity by a factor of about 2 , when pressure drops below the dew point [10].

In addition to liquid dropout, there are other issues of importance related to gascondensate production that will influence well productivity. Because of high flow rates, inertial forces are active in the reservoir, in particular close to the wellbore, where nonDarcy flow are causing an additional draw down pressure drop in the well. Several authors have been studying this problem [11-13] where numerical simulations normally are needed to distinguish the physical effects related to two-phase flow and non-Darcy flow.

Remedying the damages caused by condensate banking by reducing the drawdown pressure, i.e. such that the dew point pressure is never passed, is more easily said than done. Some sort of pressure support (dry gas, $\mathrm{CO}_{2}$ or water) might be applied, dependant on the neighboring facilities and/or economic constraints. A still more attractive method would be to reduce drawdown by increasing the inflow area and thereby linearizing the inflow pressure profile, i.e. by hydraulic fracturing [14].

\section{SCOPE OF WORK}

In this article a study on gas-condensate banking and its effect on well deliverability using two principally different models is presented; one analytical model called the Linear Dynamic Model (LD-Model) and a numerical (finite difference model) using Eclipse E300, called the Numerical Simulation Model (NS-model). Both models are sharing exactly the same reservoir, fluid and operational data.

\subsection{Reservoir data}

The reservoir is of cylindrical dimensions with the well at the center. Figure 1 shows an artistic view of a horizontal layered reservoir where gas (red color) is in part condensing (green color) in the reservoir as it flows towards the wellbore. 


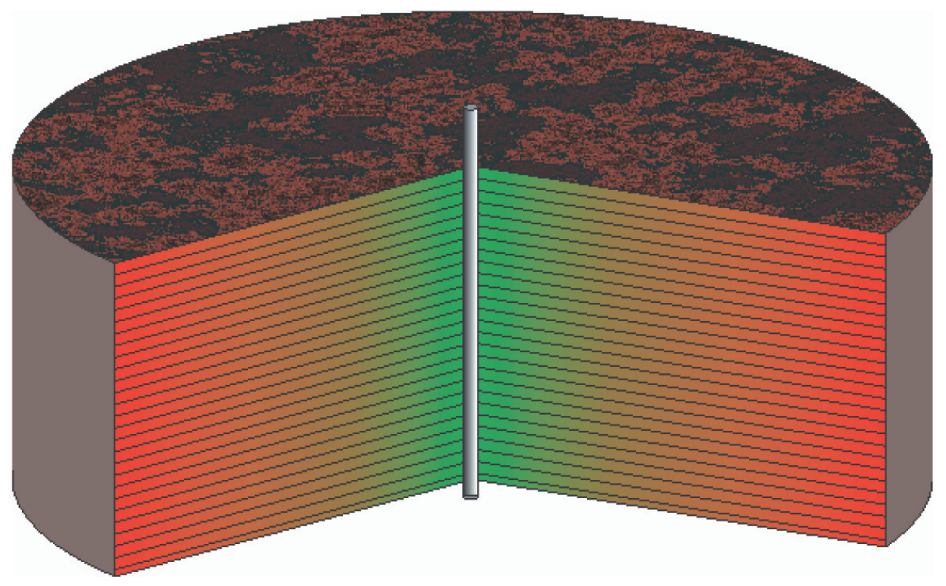

Fig. 1. Artistic view of horizontal layered reservoir

The reservoir outer boundary radius is 360 meters and the total hight is 50 meters, giving a bulk volume of $20.358 \mathrm{M} \mathrm{Rm}^{3}$. Additional reservoir data is presented in Table 1 and Table 2.

Table 1

Reservoir data

\begin{tabular}{|l|c|}
\hline Reservoir depth [m] & $z=3500$ \\
\hline Outer boundary radius [m] & $r_{e}=360$ \\
\hline Wellbore radius [m] & $r_{w}=0.011$ \\
\hline Reservoir thickness [m] & $h=50$ \\
\hline Average porosity & $\phi=0.15$ \\
\hline Average permeability [mD] & $k=10$ \\
\hline Permeability vertical/horizontal ratio [mD] & $k_{v} / k_{h}=0.1$ \\
\hline Average water saturation & $S_{w}=0.2$ \\
\hline Nett to gross ratio & $N T G=1$ \\
\hline Rock compressibility [1/bar] & $c_{r}=4.5 \cdot 10^{-5}$ \\
\hline Water compressibility [1/bar] & $c_{w}=4.35 \cdot 10^{-5}$ \\
\hline
\end{tabular}

The vertical-horizontal permeability ratio $k_{V} / k_{H}$, as given in Table 1 is securing radial flow conditions in the numerical (Eclipse) simulations.

The radial grid coordinates in Table 2 are defined according to a logarithmic increasing scale. 
Table 2

Cylindrical gridding model: 15 radial grid blocks $\times 25$ horizontal layers $(2 \mathrm{~m}$ thickness $)$

\begin{tabular}{|l|cccccccc|}
\hline $\begin{array}{l}\text { Radial coordinates } \\
{[\mathrm{m}]}\end{array}$ & 0.19 & 0.32 & 0.55 & 0.94 & 1.61 & 2.77 & 4.76 & 8.17 \\
\cline { 2 - 8 } & 14.03 & 24.10 & 41.38 & 71.07 & 122.06 & 209.62 & 360.00 & \\
\hline
\end{tabular}

\subsection{Fluid data}

The reservoir fluid is a rich gas-condensate with a GOR of $1004 \mathrm{Sm}^{3} / \mathrm{Sm}^{3}$. The molar composition of the fluid is given in Table 3 .

Table 3

Molar composition [\%] of reservoir fluid

\begin{tabular}{|l|c|c|c|c|c|c|c|}
\hline Compounds: & $\mathrm{N}_{2}$ & $\mathrm{CO}_{2}$ & $\mathrm{C}_{1}$ & $\mathrm{C}_{2}$ & $\mathrm{C}_{3}$ & $i \mathrm{C}_{4}$ & $n \mathrm{C}_{4}$ \\
\hline Composition: & 0.11 & 0.01 & 69.56 & 8.71 & 5.39 & 1.16 & 2.35 \\
\hline Compounds: & $i \mathrm{C}_{5}$ & $n \mathrm{C}_{5}$ & $\mathrm{C}_{6}$ & $\mathrm{C}_{7}$ & $\mathrm{C}_{8}$ & $\mathrm{C}_{9}$ & $\mathrm{C}^{+}{ }_{10}$ \\
\hline Composition: & 0.94 & 0.86 & 1.75 & 1.36 & 1.16 & 0.991 & 5.66 \\
\hline
\end{tabular}

The reservoir pressure and temperature is 480 bar and $398 \mathrm{~K}$, respectively. The dew point pressure, based on a single flash experiment is found to be 383 bar. The maximum retrograde liquid drop-out below the dew point pressure is estimated to approximately $32 \%$, as can be seen form Figure 2.

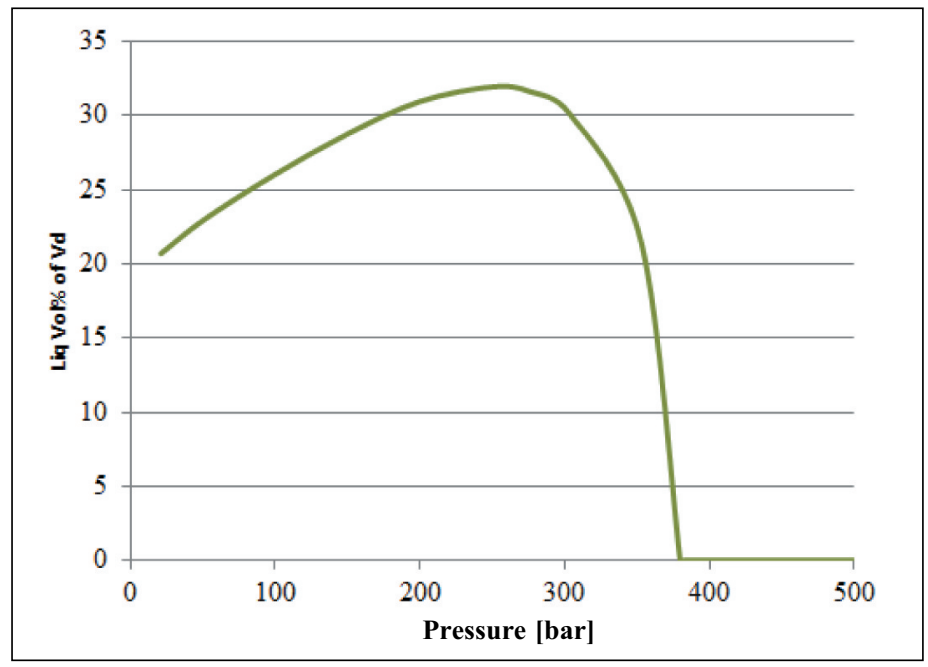

Fig. 2. Pressure vs. retrograde liquid volume (CVD experiment) 
The Peng Robinson Equation of State (EOS) with Peneloux volume correction was used to characterize the reservoir fluid, using the PVTSim software. The measured liquid dropout from the CVD experiment and the dew point pressure from the single flash experiment were used for regression analysis. The EOS model produced excellent results compared to the measured dew point pressure and liquid drop-out curve.

The calculated $Z$-factors $\left(Z\right.$ and $\left.Z_{2}\right)$, vapor-and gas viscosities $\left(\mu_{o}, \mu_{g}\right)$ and intefacial tension $\left.\sigma_{o g}\right)$, oil volume factor $\left(B_{o}\right)$ and solution gas-oil ratio $\left(R_{s}\right)$ are all obtained by PVTSim. The gas volume factor $\left(B_{g}\right)$ is calculated based on the real gas law. Plots showing these data all presented in Appendix A. (In hindsight it turns out that the numerical simulations were based on a slightly different Z-factor, as seen in Figure (a) in the Appendix A).

\subsection{Operational data}

The vertical well is producing the entire reservoir section. No hydraulic tables were generated for this study. Instead a minimum flowing bottom hole pressure of 50 bar were used. The reservoir gas was produced with a initially constant surface gas rate of $570 \mathrm{kSm}^{3} /$ day. No water production were accounted for, therefore a two phase simulation model (gas/oil) were used.

A base case scenario were simulated, where both mechanical skin $(S=0)$ and nonDarcy skin $\left(S_{n D}=0\right)$ are zero.

The calculated gas initially in place and liquid initially in place are; $G I I P=737 \mathrm{MSm}^{3}$ and $L I I P=730 \mathrm{kSm}^{3}$. (There is though a slight difference in the calculated LIIP in the two models of about 2 to $3 \%$ ).

\section{DESCRIPTION OF ANALYTICAL AND NUMERICAL MODELS}

Simulations performed by the two models are based on the same data; reservoir, fluid and operational, as described above.

The two models are principally different as they represent alternative ways of modeling reservoir production, both with respect to numerical approach as well as ways of handling the reservoir transport capacity (read: permeability).

\subsection{The Linear Dynamic Model}

The LD-model is presented in quite some detail in an earlier publication [15]. It should therefore be sufficient, in this article, to point at the main items characterizing the LD-model. 


\section{Pressure solution}

Based on a classical approach for modeling one phase gas flow in a cylindrical reservoir with the well at the center, using Kirchhoff's transformation and application of pseudo pressures, the following pressure solution is reached,

$$
\bar{m}-m_{b h}=\frac{q_{s c}\left(\mu B_{g}\right)_{r}}{2 \pi h k}\left(\ln \frac{r_{e}}{r_{w}}-\frac{3}{4}+S+S_{n D}\right)
$$

Eq. (1) is a solution of the diffusivity equation under semi steady-state conditions, where the bottom-hole pseudo pressure $m_{b h}$ is given as function of the reservoir mean pressure $\bar{m}$ at constant surface flow rate $q_{s c}$. $\left(\mu B_{g}\right) r$ is the gas viscosity times the volume factor for gas, measured at a reference pressure (normally lower than the dynamic pressures used). $S$ and $S_{n D}$ are the mechanical skin and non-darcy skin, respectively. The reservoir parameters $h, k, r_{e}$ and $r_{w}$ are hight of reservoir, absolute permeability, outer boundary radius and wellbore radius, respectively.

Expansion of Eq. (1) to two-phase flow is simply done by redefining the transformation defining the one to one correspondence between pressure $p$ and pseudo pressure $m$, defined by the transformation,

$$
\nabla m=\frac{d m}{d p} \nabla p=\frac{k_{r g} \frac{\rho_{g}}{\mu_{g}}+k_{r o} \frac{\rho_{o}}{\mu_{o}}}{\left(k_{r g} \frac{\rho_{g}}{\mu_{g}}+k_{r o} \frac{\rho_{o}}{\mu_{o}}\right)_{r}} \nabla p
$$

The bottom-hole pressure development are calculated based on Eqs. (1) and (2), when the parameters $\rho_{g}, \rho_{o}, \mu_{g}, \mu_{o}, k_{r g}$ and $k_{r o}$ are known.

\section{Definition of parameters}

The reservoir fluid densities $\rho_{g}$ and $\rho_{o}$ are defined by material balance calculations and are generally functions of volume factors and surface densities,

$$
\begin{gathered}
\rho_{g}=\frac{1}{B_{g}}\left(\rho_{g n}+r_{s} \rho_{o n}\right) \\
\rho_{o}=\frac{1}{B_{o}}\left(R_{s} \rho_{g n}+\rho_{o n}\right)
\end{gathered}
$$

where $B_{g}, B_{o}, R_{s}$ and $r_{s}$ are volume factors of gas, oil, and solution gas-oil and solution oilgas ratio, respectively, $\rho_{g n}$ and $\rho_{o n}$ are the gas and oil densities at normal condition, respectively. 
The viscosities $\mu_{g}$ and $\mu_{o}$ are taken from the literature and readily calculated as function of known parameters [16]:

$$
\mu_{g}=K \cdot e^{X \rho_{g}^{Y}}
$$

where $K, X$ and $Y$ are functions dependent on temperature and average molar weight.

For oil viscosity the following empirical formula is used [17]:

$$
\ln \left(\mu_{o}\right)=-2.65+8.48 \rho_{o}^{4}
$$

Definition of relative permeability $k_{r}$ for oil and gas are in this work based on published experimental investigations and theoretical calculations on immiscible fluids [18], where wetting and non-wetting relative permeabilities are presented as function of an effective saturation $S_{\text {eff: }}$

$$
\begin{gathered}
k_{r w}=\left(S_{\text {eff }}\right)^{\frac{2+3 \lambda}{\lambda}} \\
k_{r n w}=\left(1-S_{\text {eff }}\right)^{2}\left(1-S_{\text {eff }}^{\frac{2+\lambda}{\lambda}}\right)
\end{gathered}
$$

Figure 3 a shows the proposed relative permeabilities as function of effective saturation for two choices of $\lambda$ (called the pore size distribution index of the medium); equal to 15 and 0.5 , respectively.

Based on these permeabilities, the non-wetting relative permeability (here: gas rel.perm., $k_{r g}$ ) can be plotted as function of the ratio of non-wetting permeability over wetting permeability, such that in the gas-oil case, we may write: $k_{r g}=k_{r g}\left(k_{r g} / k_{r o}\right)$. Figure $3 b$ shows this functional relationship for different values of $\lambda(15,1,0.5$ and 0.1$)$.

The ratio $k_{r g} / k_{r o}$ can be expressed by a dynamical expression derived from Darcy's law [10]:

$$
\frac{k_{r g}}{k_{r o}}=\frac{R_{p}-R_{s}}{1-R_{p} r_{s}} \frac{\mu_{g} B_{g}}{\mu_{o} B_{o}}
$$

where $R_{p}$ is the dynamical GOR: $\left(R_{p}=\Delta V_{g n} / \Delta V_{o n}\right) . R_{s}$ and $r_{s}$ are both found by PVT calculations.

In the equation above:

$$
\begin{aligned}
& \text { when } p \geq p_{\text {dew }} \Rightarrow R_{p}=1 / r_{s} \text { and } k_{r g}=1, k_{r o}=0, \\
& \text { when } p<p_{d e w} \Rightarrow R_{p}<1 / r_{s} \text { and } k_{r g} / k_{r o} \text { is well defined and finite. }
\end{aligned}
$$

From Eq. (9) and Figure $3 \mathrm{~b}$ it is clear that if $R_{p}$ can be found, then the relative permeability $k_{r}$ for gas and oil can be calculated and thus Kirchhoff's transforation, Eq. (2) is readily obtainable and as such also the bottom hole pressure expressed in Eq. (1). 
a)

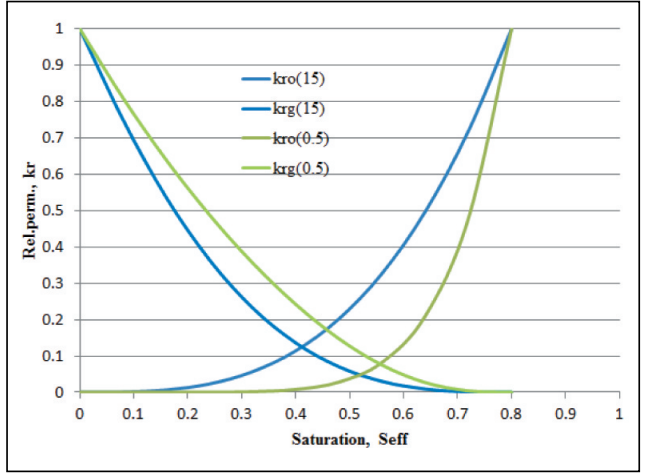

b)

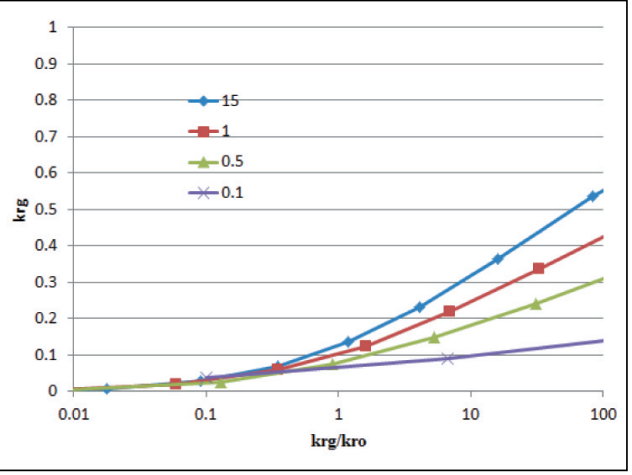

Fig. 3. Relative permeability based on synthetic data. Relative permeability: $k_{r g}$ and $k_{r o}$ (a). Functional relationship: $k_{r g}=k_{r g} / k_{r o}(\mathrm{~b})$

\section{Modeling of immobile oil volume: $V_{c o}$}

The key element in calculating $V_{c o}$ is related to the assumption that there exist a saturation of condensed immovable oil remaining in the reservoir. As pressure is declining below the dew point pressure, this saturation can be represented as a dynamical changing oil saturation radially progressing from the wellbore as function of time, $S_{o}(r, t)$.

When the first droplets of oil condenses in the close vicinity of the wellbore, the lighter gas will flow to the surface while the liquid oil will remain in the reservoir and is considered lost production. As pressure is decreasing due to normal gas production, the saturation of oil in the reservoir will increase until the oil becomes continuous and the saturation reaches its critical level. This situation occurs locally and will with time eventually reside in the whole reservoir volume. In those parts of the reservoir where the oil saturation already has reached its critical saturation, additional condensed oil will form a separate oil phase, causing two phase flow in the reservoir.

For a certain point in time, in the production period of a gas condensate reservoir, the oil saturation profile of the immobile oil in the reservoir could be modeled as shown in Figure 4.

The saturation of immobile oil, in Figure 4, is an explicit function of the radial position $r$ :

$$
S_{o}(r)= \begin{cases}S_{c o}\left(\frac{r-r_{w}}{r_{c o}-r_{w}}\right)^{L 1} & r_{w} \leq r<r_{c o} \\ S_{c o}\left(\frac{r_{d e w}-r}{r_{d e w}-r_{c o}}\right)^{L 2} & r_{c o} \leq r<r_{d e w} \\ 0 & r_{d e w} \leq r<r_{e}\end{cases}
$$




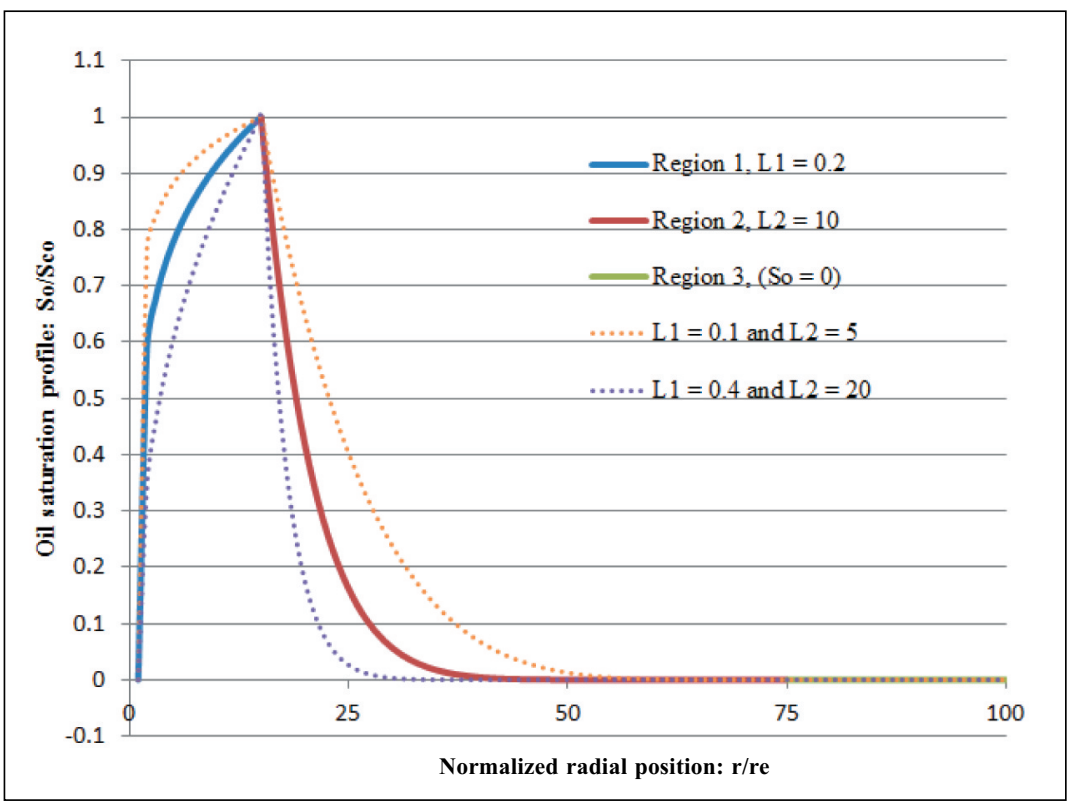

Fig. 4. Normalized oil saturation as function of relative reservoir position

The wellbore radius, $r_{w}$ is constant while the position in the reservoir where the oil saturation reaches its critical level, represented by $r_{c o}$, and the position where the pressure drops below the dew-point pressure, given by $r_{d e w}$, are both functions of time, indirectly dependent on the pressure development in the reservoir [15].

The constants $L 1$ and $L 2$ defines the shape of the saturation profile, as seen in Figure 4, and can be subject for sensitivity analysis. The critical saturation $S_{c o}$, on the other hand, is characterizing the reservoir storing capacity of immobile oil. If $S_{c o}$ is low, not much oil is stored in the reservoir and two phase flow will commence quite early in the production period. If $S_{c o}$ is high, much of the gas condensate oil might be produced before reduced well deliverability is experienced, due to two phase flow in the reservoir.

Based on the saturation model defined by Eq. (10) and Figure 4, the volume of immobile oil in the reservoir, $V_{c o}$, is simply the integration over the whole reservoir volume:

$$
V_{c o}=2 \pi h \phi\left(1-S_{w}\right)\left[\int_{r_{w}}^{r_{c o}} r S_{o}(r) d r+\int_{r_{c o}}^{r_{d e w}} r S_{o}(r) d r\right]
$$

Eq. (11) has an analytical solution where $r_{c o}$ and $r_{\text {dew }}$ are the dynamic parameters, determining the radial development of the saturation profile with time.

The immovable oil saturation in the reservoir, based on the above model, can be evaluated as function of time and is presented in Figure 5. The figure shows the normalized oil saturation $S_{o} / S_{c o}$ as function of normalized radial position $r / r_{e}$ and production 
time. During the first 80 to 90 days, no condensation takes place in the reservoir, as the pressure is higher than the dew point pressure in all parts of the reservoir. After this time and up to about 700 days, a saturation of oil condensate is building up in the close vicinity of the wellbore, where the region further in to the reservoir is characterized by low to no condensation. From about 700 days to about 900 days, the oil saturation is radially advancing deeper into the reservoir. This process is further continuing as gas production is entering into its final stage, where the production rate is controlled by a minimum bottom hole pressure.

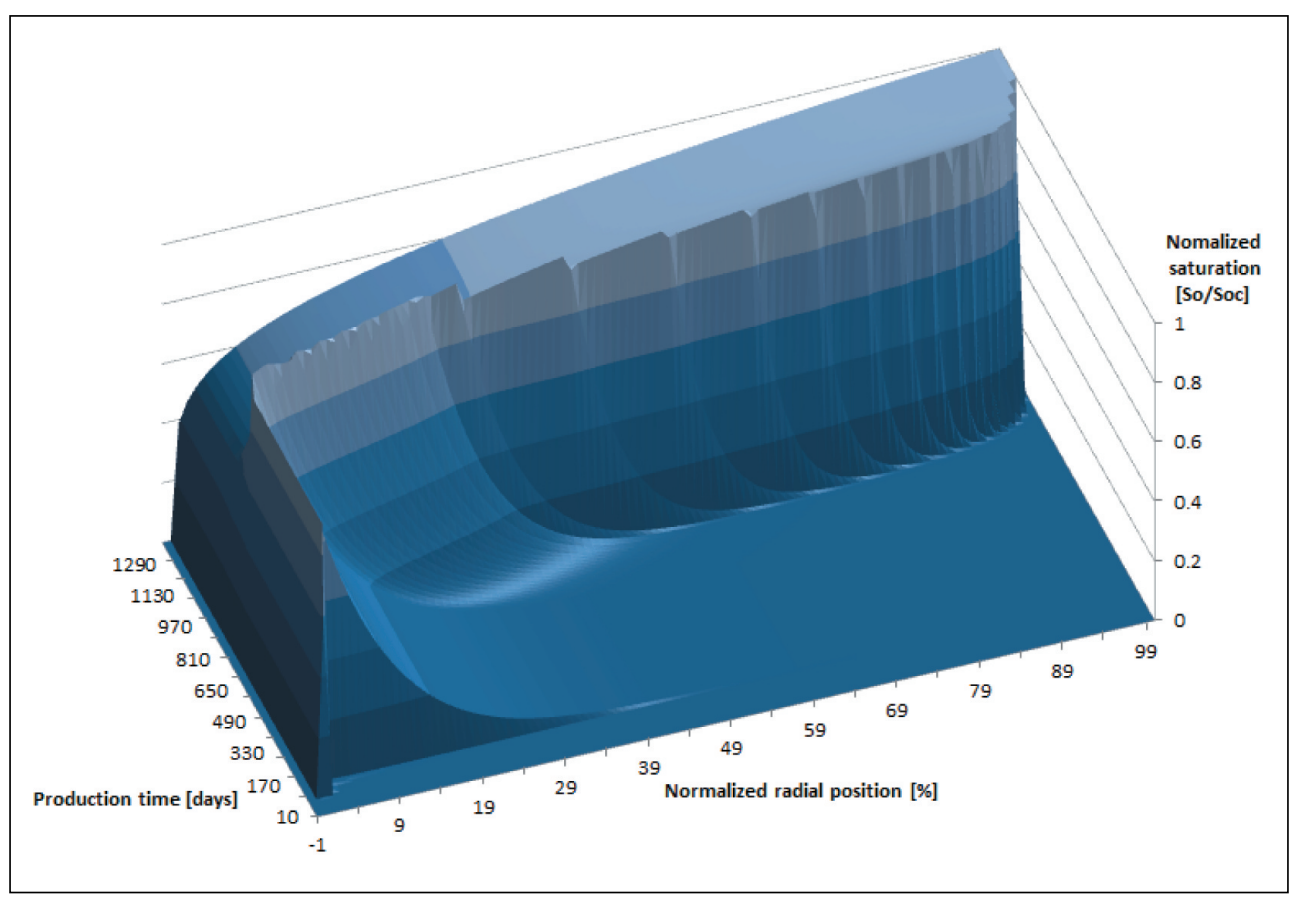

Fig. 5. Normalized immovable oil saturation in the reservoir as function of normalized radial position and production time, where $L 1=0.2, L 2=10$ and $S_{c o}=0.6$

The two phase flow of oil and gas in the reservoir is, in part, characterized by the saturation profile shown in Figure 5, as the oil flowing into the wellbore is the excess cumulative oil condensed in the reservoir, not being part of the immobile reservoir oil.

\section{Modeling of GOR: $\boldsymbol{R}_{\boldsymbol{p}}$}

In lean gas condensate reservoirs, all liquid dropout is considered lost production and therefore remain in the reservoir. Thus, no oil is flowing and single phase flow resides in the reservoir. In these cases the GOR is defined as the ratio between surface gas produced, $G_{p}$ and liquid produced $G_{L p}$, i.e. $R_{p}=G_{p} / G_{L p}$. 
In rich gas condensates, however, the reservoir oil storing capacity are exceeded, in particular in the close vicinity of the wellbore, and the excessive oil will flow alongside the gas towards the well. The volume of extra oil produced to the surface, as part of this two phase flow, is therefore the difference between the volume of cumulative oil, $V_{o}$, that drops out of the gas in the reservoir, using standard calculating techniques, and the volume of oil stored in the reservoir $V_{c o}$, as depicted in Figure 5.

The part of reservoir oil that is produced, is therefore the difference, $\Delta V_{o}=V_{o}-V_{c o}$. At the surface this volume split into an oil and a gas part, where these volumes are defined as:

$$
\Delta V_{\text {ogn }}=\frac{R_{S}}{B_{o}} \Delta V_{o} \quad \text { and } \quad \Delta V_{\text {oon }}=\frac{1}{B_{o}} \Delta V_{o}
$$

The production GOR, $R_{p}$ which is defined as the ratio of total surface produced gas and oil, is therefore defined as:

$$
R_{p}=\frac{G_{p}+\Delta V_{o g n}}{G_{L p}+\Delta V_{o o n}}
$$

Finding $R_{p}$, is the final step in the process of calculating the relative permeabilities $k_{r g}$ and $k_{r o}$, defined by Eq. (9) and Figure 3.

\section{LD-model base case simulations}

A base case simulation is presented based on the reservoir-, fluid- and operational data presented above (see section Scope of Work).

In Figure 6 the pressure development of single phase gas flow (nof: no oil flow) is compared to the case where two phase flow is calculated using the LD-model. The reddish colored curves show the single gas flow case while the greenish colored curves show the two phase flow behavior. The production is characterized by constant surface gas flow rate of $570 \mathrm{kSm}^{3} /$ day up to about 900 days where the production rate is adjusted to a constant minimum bottom hole pressure of 50 bars.

As seen in Figure 6, liquid condensation starts already after about 90 days, while two phase flow commences after about 200 days of production. During this time period of about 100 days, an oil saturation is building up in the close vicinity of the well. When this oil saturation has reached its critical value (dependent on the storing capacity of the reservoir rock, characterized by a critical oil saturation; $S_{c o}$ ) additional condensed oil will start to flow towards the well.

As the bank of immovable oil is expanding radially into the reservoir, caused by a decreasing reservoir pressure, the excessive liquid phase is produced to the surface. This process continues until the volume of liquid condensation in the reservoir equals the available local storing reservoir capacity. When this happens, all liquid condensed will be part of the immovable bank of oil gradually and radially progressing into the reservoir. As the pressure decreases, also the rate of condensation may also decrease, 
given by the PVT phase envelope characteristics. In Figure 6 this happens after about 700 days, whereafter the wellbore pressure development is defined by single gas flow.

Figure 6 shows an other interesting detail related to the effect of two phase flow in the reservoir. The reduced bottom hole pressure due to two phase flow behavior have a cost as relative more energy is spent producing the gas to the surface. This additional use of energy is taken from the pressure energy stored in the reservoir, reducing the level of mean energy, as can be seen in the figure (as difference between the red and green curves).

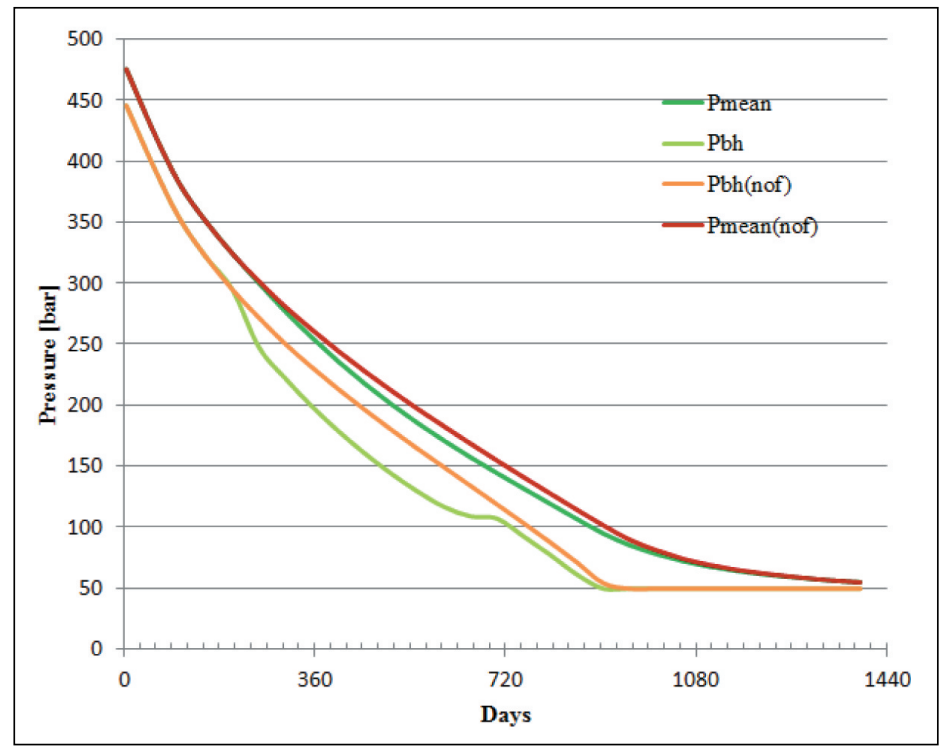

Fig. 6. Reservoir mean pressure and bottom hole pressure for two cases of single phase gas flow (nof: no oil flow) and two phase flow

a)

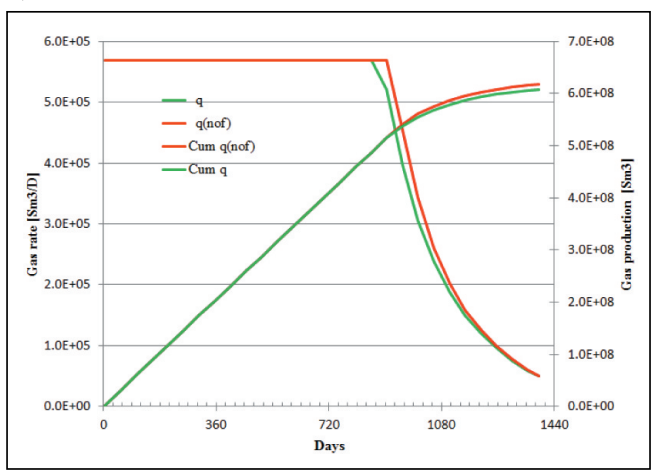

b)

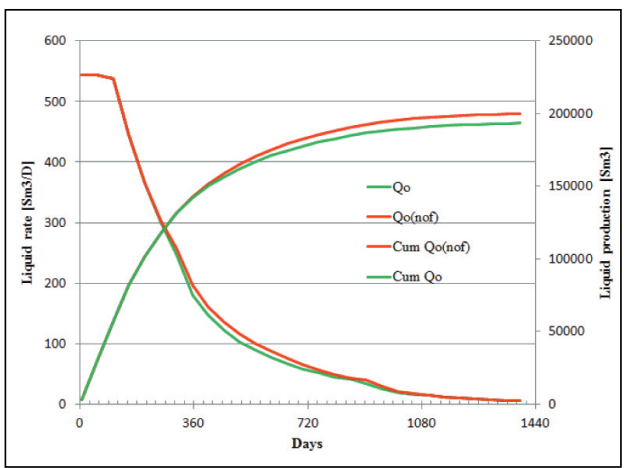

Fig. 7. Gas- and gas condensate rates and cumulative production as function of time in days. Gas rate and gas production (a). Oil rate and gas production (b) 
Gas and condensate production are both influenced by two phase flow in the reservoir, as can be seen from Figure 7. In the nof case, constant gas production is maintained somewhat longer than in the two phase case (Fig. 7a) and consequently some more gas is cumulatively produced. This effect is also seen for liquid oil production, even so additional oil is produced due to two phase oil production, the cumulative effect is a reduction in oil production in the two phase case.

\subsection{The numerical simulation model}

A cylindrical reservoir model with a centered well was build, using the Eclipse 300 compositional reservoir simulator. Data related to the reservoir is presented in Table 1 and data containing gridding and layering information are presented in Table 2 .

The vertical well is perforated in the whole reservoir section (50 meter) and the netto/gross ratio is 1 . The reservoir is produced against a minimum bottom hole pressure of 50 bar and therefore no hydraulic table was used in the NS-model. No free water is modeled and therefore no water production is recorded. The oil-gas capillary pressure is assumed to be zero.

\section{Base case simulations}

One of the key elements in the LD-model is its independence of explicit relative permeability data, as described above. Therefore no relative permeability data is provided for this study.

In the NS-model, however, relative permeability data is needed to perform the simulations. For this purpose, synthetic rel.perm. data were generated using the Corey equations. Table 4 is listing Corey exponents, saturations and end point rel.prem. used.

Since water is not flowing in the model, only rel.perm. curves for gas and oil are used; $k_{r o}$ and $k_{r g}$, as seen in Figure 8. In the figure, both miscible and immiscible rel.perm. curves are presented, as it is assumed that these curves represent extreme flow regimes. The most likely rel.perm. curves is assumed to be something in between the two extreme curves. The miscible and immiscible curves in Figure 8 would therefore simulate the most favorable and worst case scenarios when condensate blockage and reduced well deliverability are questioned.

The bottom hole pressure development for the LD- and NS-models are shown in Figure 9. No water is produced nor is any aquifer water influx modeled in either cases.

In the analytical model (LD-model); $L 1=2$ and $L 2=10$. The figure shows two simulations where the critical saturation, i.e. the reservoir storing capacity, is $S_{c o}=0.6$ (base case) and $S_{c o}=0.3$ (blue curve). As can be seen from the figure and what could be expected, is that the onset and duration of two phase flow in the reservoir comes on earlier and lasts longer, in the case of lower reservoir storing capacity.

The bottom hole pressure developments for the NS-model are indicated by broken lines (valid for all NS-model data), were pressures recorded for the miscible and immiscible simulations show quite different behavior during the time period of constant surface rate production. 
Table 4

Corey exponents, saturations and end point rel.perm

\begin{tabular}{|l|l|}
\hline \multicolumn{2}{|l|}{ Corey exponents: } \\
\hline Gas, $n_{g}$ & 3.50 \\
\hline Oil to gas, $n_{o g}$ & 4.50 \\
\hline Water, $n_{w}$ & 2.50 \\
\hline Oil to water, $n_{\text {ow }}$ & 3.50 \\
\hline Saturations: & \multicolumn{2}{|l}{} \\
\hline Irreducible water saturation, $S_{\text {wir }}$ & 0.20 \\
\hline Critical gas saturation, $S_{g c}$ & 0.05 \\
\hline Residual oil saturation (in water), $S_{\text {orw }}$ & 0.25 \\
\hline Residual oil saturation (in gas), $S_{o r g}$ & 0.25 \\
\hline End point rel.perm.: & \\
\hline Oil rel.perm. at $S_{w i r}$ & 1.00 \\
\hline Water re.perm. at $S_{\text {orw }}$ & 0.35 \\
\hline Oil rel.perm. at $S_{\text {wir }}$ & 1.00 \\
\hline Gas rel.perm. at $S_{\text {gmax }}$ & 1.00 \\
\hline
\end{tabular}

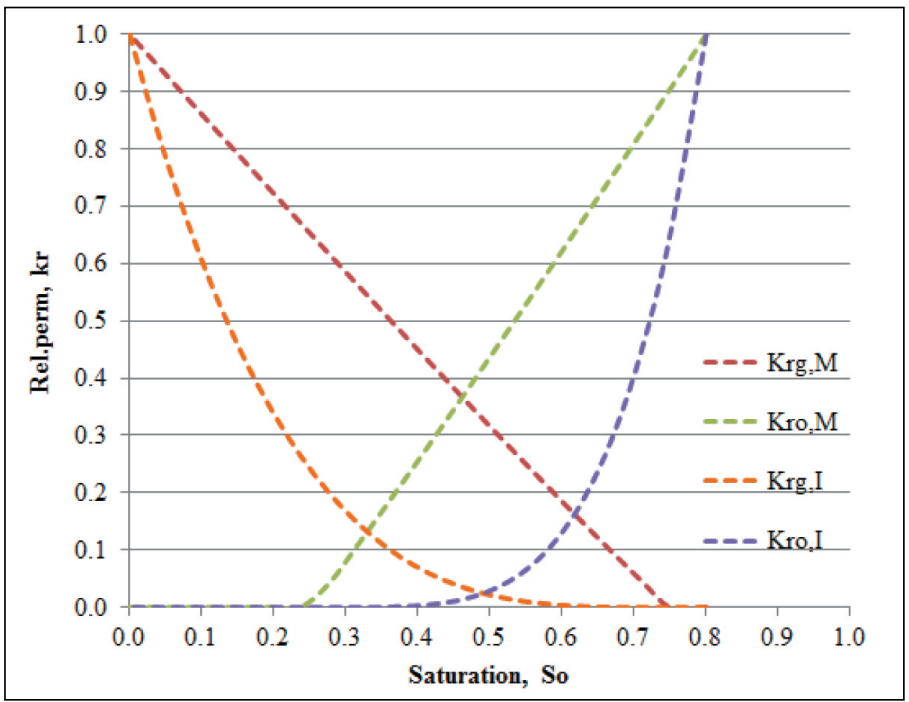

Fig. 8. Relative permeability curves generated from the Corey equations for miscible and immiscible flow 
From observing the bottom hole pressure development in Figure 9, it seems that the onset of two phase flow in the reservoir is treated differently in the two models. In the NSmodel, two phase flow in the reservoir starts immediately after the bottom hole pressure has fallen below the dew point pressure, at around 50 days of production, while in the LD-model, the increased pressure drop occurs after about 200 days. The delayed onset of two phase flow in the LD-model is caused by the time it takes for enough oil to fill up the pore volume and build up a critical saturation of immovable oil. The delayed onset of two phase flow in the LD-model is therefore directly related to the storing capacity of the reservoir.

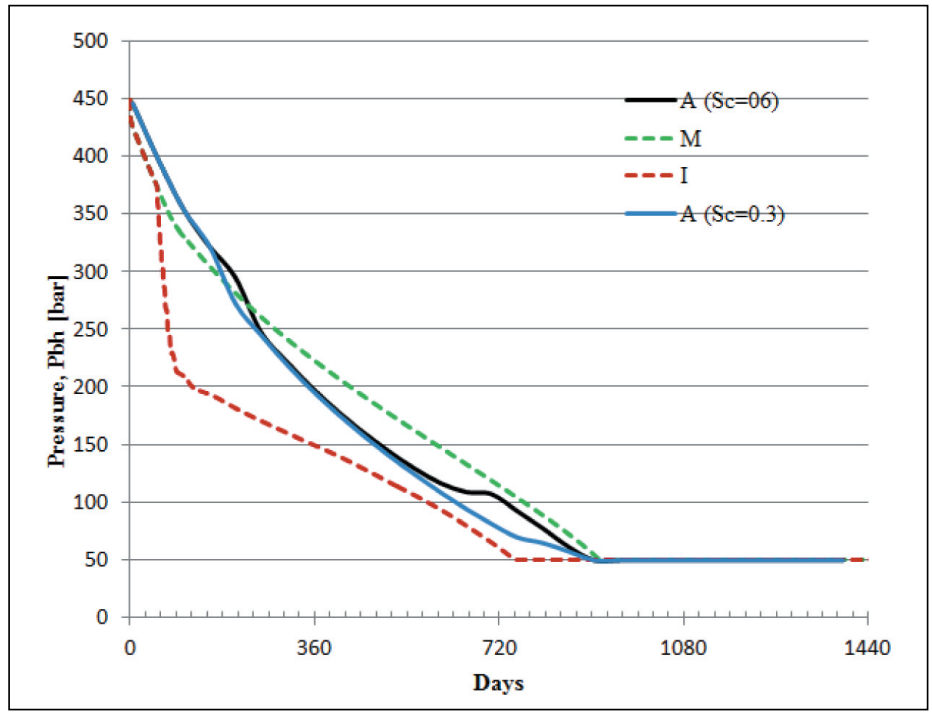

Fig. 9. Bottom hole pressure development in the reservoir using the two models

a)

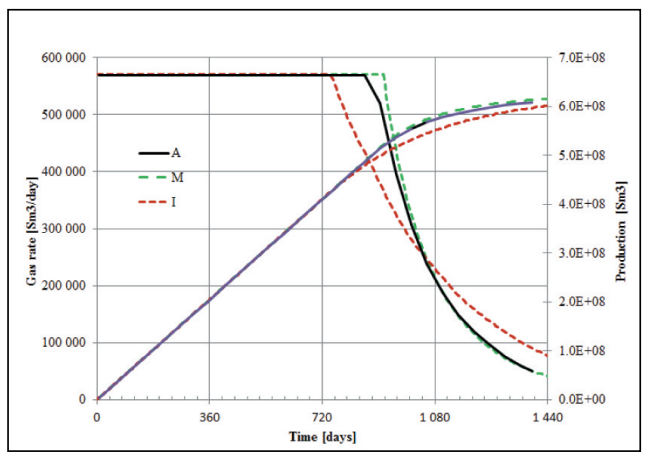

b)

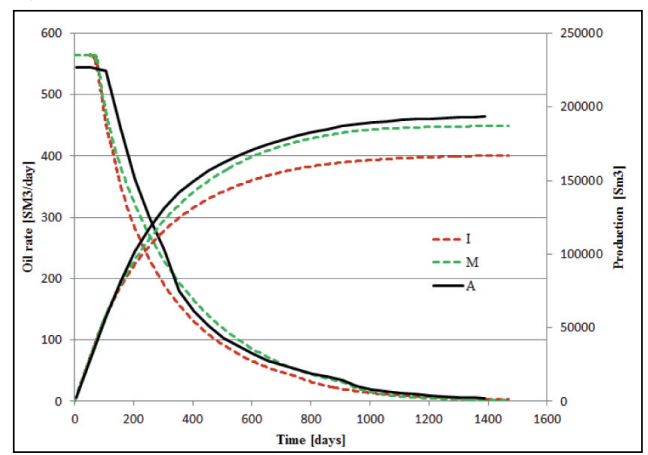

Fig. 10. Comparison of flow rate and cumulative production.

Gas rate and cumulative production (a). Oil rate and cumulative production (b) 
Rate and production data, presented in Figure 10, show that the production of gas and oil in LD-model resembles more the miscible than the immiscible case in the NS-model, but generally that the LD-data falls in between the two NS-data sets. There is a slight discrepancy between the liquid rate in the two models (see Fig. 10b) that is probably due to different molar split factors used in the two models.

\section{COMPARING THE LD AND NS MODELS}

In this section some comparisons are made in order to certify the LD-model in comparing it to the NS-model.

\subsection{Productivity index: $P I$}

The productivity index is a way of expressing the ability of the reservoir to deliver i.e. gas and oil fluids to the well bore. As such, the productivity index is revealing facts both related to the reservoir and the fluid therein.

The productivity index is commonly defined as:

$$
P I=\frac{q}{\bar{p}-p_{w}}
$$

where $q$ is the surface flow rate, $\bar{p}$ is the mean reservoir pressure and $p_{w}$ is the wellbore pressure.

The $P I$ index is readily obtainable based on the simulation data at hand. Figure 11 shows the normalized productivity index $P I / P I\left(p_{i}\right)$ for gas- and oil production, respectively.

a)

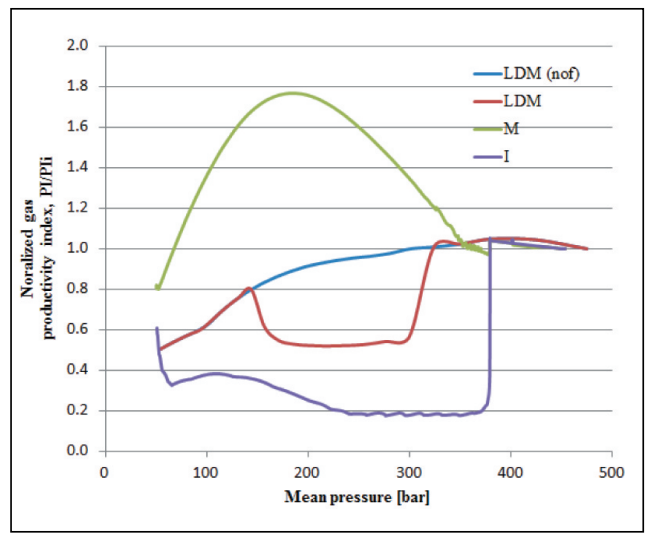

b)

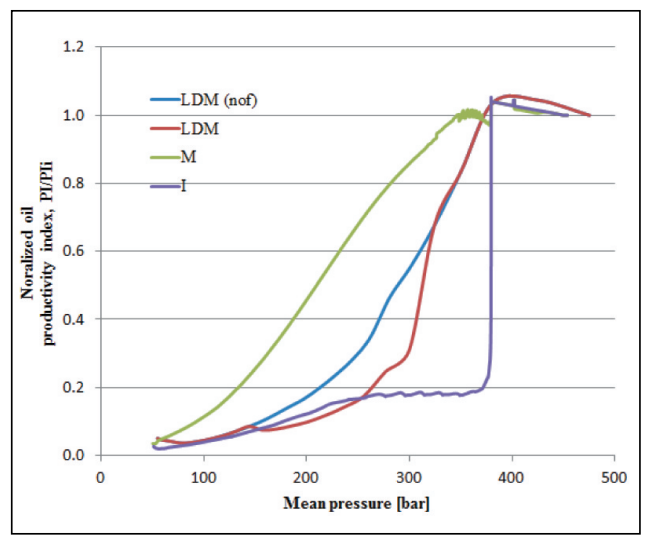

Fig. 11. Normalized productivity index for gas- and oil production. PI for gas production (a). PI for oil production (b) 
As can be observed from Figure 11, there are large differences between the two models, but even larger differences within the NS-model and generally we observe that the PI related to LD-data falls in between the miscible and the immiscible cases.

The productivity indexes for miscible and immiscible flow behave very different and as such describes quite different reservoir characteristics with respect to fluid productivity, in particular in the gas case. The difference between the miscible- and immiscible cases is striking to such a degree that it is difficult to realize how a mean rel.perm. curve can based on an averaging procedure using the curves presented in Figure 8 (to be discussed later in this article).

The $P I$ index based on data from the LD-model show similar behavior to the immiscible case, in particular for the gas data. The blue curve in Figure 11a, shows the no flow case, were all oil condensed will remain in the reservoir, i.e. no two phase flow.

In order to bring more clarity in interpreting the production indexes as shown in Figure 11, some simple deductions/assumptions can be made.

Applying Darcy law to Eq. (14), the gas productivity index can be approximated:

$$
P I_{g} \propto \frac{k_{g}}{\mu_{g} \cdot B_{g}}
$$

where $k_{g}$ is the effective gas permeability, $\mu_{g}$ and $B_{g}$ are the viscosity and volume factor, respectively.

The volume factor for gas is approximated; $B_{g} \propto z / p$, using the definition of $B_{g}$ and the real gas law. The effective permeability $k_{g}$ is assumed to be a function of an effective saturation that can be associated to the oil saturation as seen in Figure 8. The effective saturation is approximated by $S_{g}=1-S_{o}$ and will decrease as the pressure in the reservoir decreases. We may therefore associate the effective gas permeability with the reservoir pressure, such that:

$$
k_{g} \propto\left(\frac{p}{p_{\text {dew }}}\right)^{n}
$$

where $p_{\text {dew }}$ is the dew point pressure, $n$ is an index equal to 1,2 or 3 and the pressure $p=\left[p_{\text {min }}, p_{\text {dew }}\right]$. Eq. (16) is justified following an argument that the effective permeability is observed to be approximately proportional to the gas saturation in the miscible case (for $n=1$ in Eq. (16)), as seen in Figure 8. In the immiscible case, this relationship is seen to become nonlinear and is therefore modeled by an index $n>1$ in Eq. (16). The approximation in Eq. (16) gives an assumption of how fast the effective gas permeability are changing when modeling the $P I$ changes as seen in Figure 11a. Figure 12 shows the normalized $P I$ index defined by Eq. (15). 


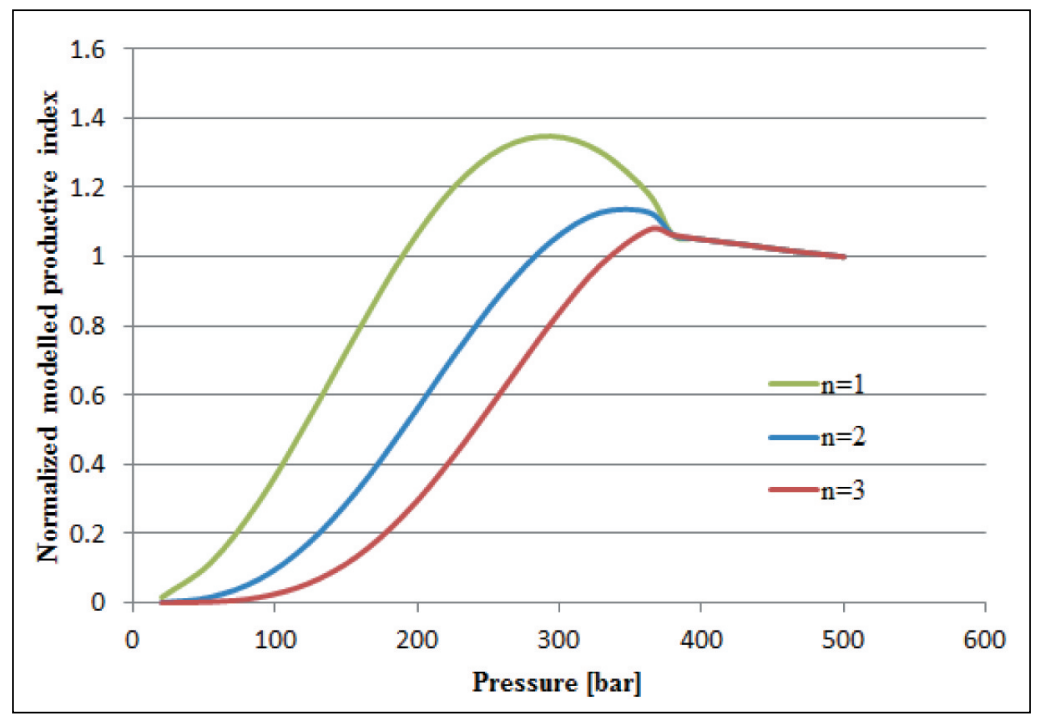

Fig. 12. $P I_{g} / P I_{g}\left(p_{\text {dew }}\right.$ model based on Eq. (14))

Comparing Figures 12 and 11a we see that:

- The miscible cases behave similarly in the two figures. The normalized productive index for miscible data in the ND-model seems to be somewhat over optimistic while on the other hand the productivity index for the immiscible data looks very pessimistic.

- The normalized productive index representing the LD-data compares well with the model in Figure 12, as it clearly show the nonlinear relationship when two phase flow commences in the reservoir.

- The rather drastic changes in gas productivity is caused by quite fast and abrupt decrease in effective gas permeability when two phase flow sets in.

\subsection{Effect of non-Darcy skin}

The non-Darcy skin effect is introduced into the flow equations in the LD-model, much the same way the mechanical skin is introduced into the pressure equation, as can be seen in Eq. (1). Different from the mechanical skin, the non-Darcy skin is proportional to the surface flow rate; $S_{n D}=q_{s c} \cdot D$, where $D$ is the non-Darcy skin factor.

In these simulations we have used a non-Darcy skin factor; $D=5 \cdot 10^{-6}$ day $/ \mathrm{Sm}^{3}$, which then gives a non-Darcy skin; $S_{n D}=2.85$ for a maximum flow rate of $5.7 \cdot 10^{5} \mathrm{Sm}^{3} /$ day.

The effect of the non-Darcy skin is to introduce an additional pressure drop in the reservoir due to the assumed influence of turbulent flow behavior in the near wellbore region. This additional pressure drop brings about an early depart form the constant surface flow regime, as seen in Figure 13b, and lead eventually to a delayed production of gas and oil. 
a)

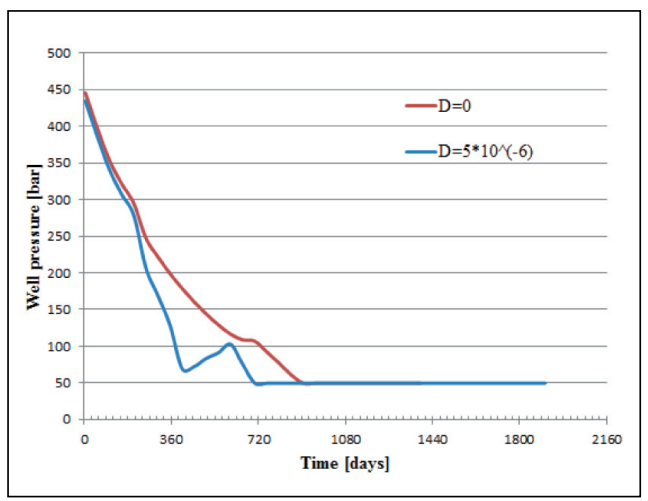

b)

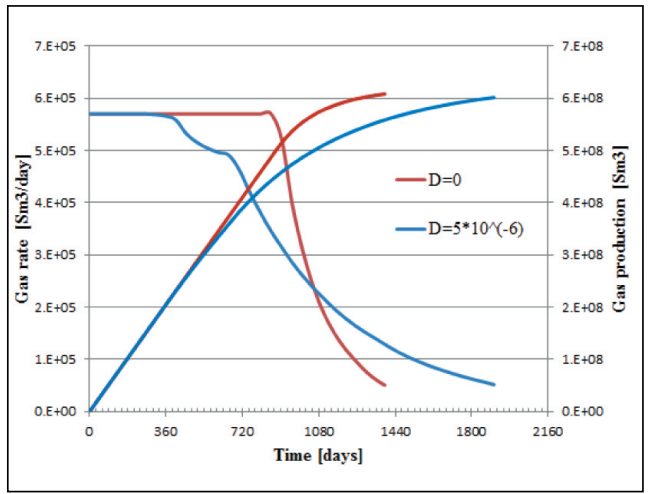

Fig. 13. Non-Darcy skin effect. Pressure development (a).

Fluid rate and production (b)

The figures (Fig. 13a and b) show pressure development, flow rate and cumulative rate for two cases, with and without non-Darcy skin. A critical oil saturation; $S_{c o}=0.6$ are used in both cases.

The non-Darcy skin simulated with the NS-model is seen in Figure 14. The bottom hole pressure effect of the non-Darcy skin data is by far more pronounced in the immiscible cases than in the miscible case, as should be expected. The early pressure drop in the immiscible cases, shown in Figure 14a, seems not to trigger such an early depart form constant surface flow rate, as can be seen in the LD-data. A possible explanation to this fact could be the deep drop in the bottom hole pressure seen in the LD-data (Fig. 14a), deeper than the sudden drop in the immiscible cases. The LD- modeled deep pressure drop, is deep enough to triggers an early depart form the constant surface flow rate, as the pressure drops below the minimum bottom hole pressure of 50 bars.

a)

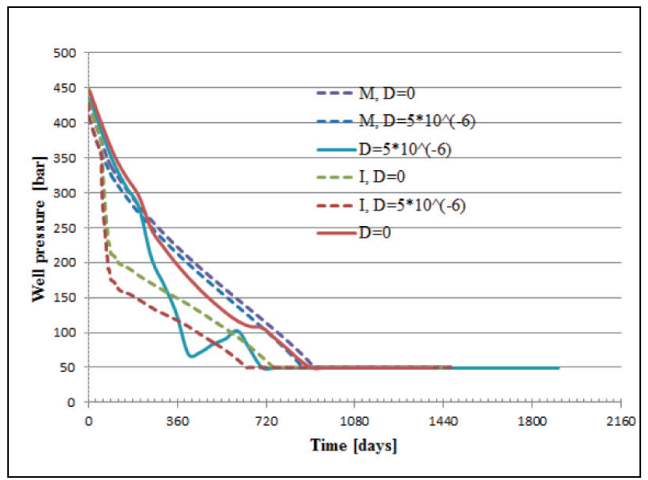

b)

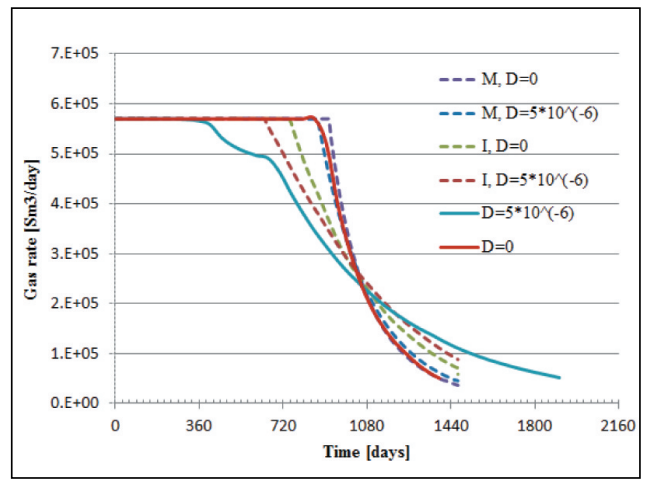

Fig. 14. Non-Darcy skin effects, comparing the LD and ND models.

Pressure development (a). Fluid rate (b) 
Finally the non-Darcy skin effect is compared to the effect of mechanical skin, where $S=2.85$, equal to the non-Darcy skin for maximum flow rate as seen above. Figure 15 shows the well bore pressure, flow rate and cumulative flow rate for the three cases of; $\left(S=S_{n D}=0\right),\left(S=0\right.$ and $\left.S_{n D}=5 \cdot 10^{-6} \cdot q_{s c}\right)$ and $\left(S=2.85\right.$ and $\left.S_{n D}=0\right)$.

As shown in the figure, the effect of mechanical skin is much less significant then the non-Darcy skin.

a)

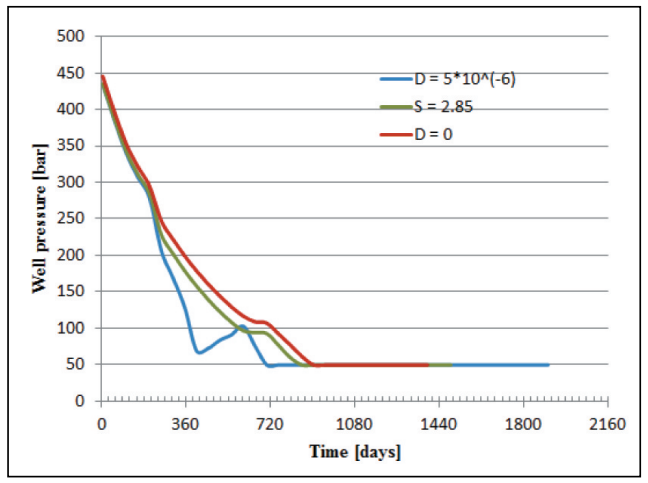

b)

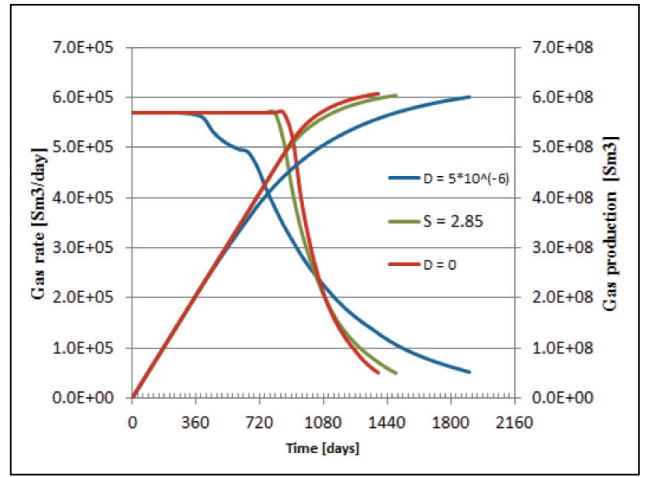

Fig. 15. Comparison non-Darcy skin and mechanical skin. Pressure development (a). Fluid production (b)

\subsection{Sensitivity on reservoir permeability}

Well deliverability is closely related to the overall reservoir permeability. If the wellbore pressure drop is significant, then additional pressure drop caused by condensate blockage or non-Darcy flow behavior will reduce well deliverability. According to the literature, this condition appears when the product of permeability and formation thickness is low, i.e. when formation $k h<3000 \mathrm{mD} \cdot \mathrm{m}$.

Figure 16 shows reduction in normalized plateau length as function of $k h$, i.e. reductionin absolute reservoir permeability. The figure shows a comparison between the miscibleand immiscible flow in the NS-model and simulations using the LD-model with and without non-Darcy flow corrections. The assumption in the literature of a reduction in well deliverability at about $3000 \mathrm{mD} \cdot \mathrm{m}$, seems to be confirmed by the two models.

\section{Modeling mean rel.perm.: $\overline{k_{r g}}$ and $\overline{k_{r o}}$}

Up to this point we have compared the results of the LD-model with simulations using two rather extreme rel.perm. curves in the NS-model, represented by miscible and immiscible flow conditions. From the above observations it seems right to note that nearmiscible permeability functions compares better to the simulation using the LD-model, 
but a combination of the two flow conditions, miscible and immiscible, should be give a more "correct" and better basis for comparing the two models.

The difference between the two extreme functions in the NS-model depend on the ratio of viscous to capillary forces on a pore scale, and can be denoted by the capillary number, $N_{c}$. A large number of methods have been proposed and evaluated in the literature, where the capillary number has been included in the gas condensate relative permeability functions.

In one of these evaluations [19], a weighting function proposed by Whitson and Fevang is found to be the most convenient method to combine miscible and immiscible representation of flow conditions using the capillary number (see also reference [20]. This method covers the entire range of capillary numbers and is said to be able to reproduce the most important aspects of the dependance of relative permeability on the capillary number, with a restricted number of parameters. The method is also said to be well adapted for interpolation of Corey coefficients.

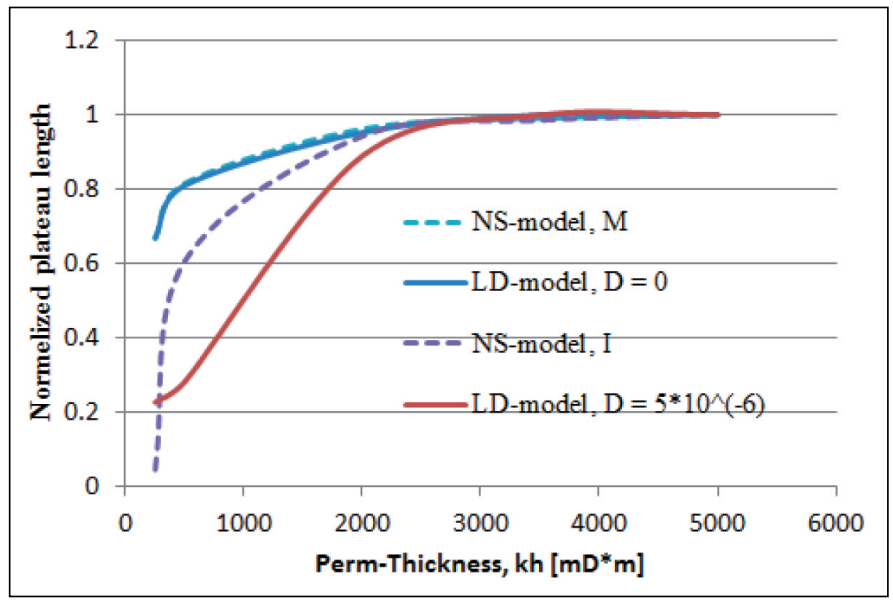

Fig. 16. Relative plateau length as function of $k h$ for the LD- and NS-models

In the model proposed by Whitson and Fevang, an average rel.prem. function is seen as a weighted mean of the miscible and immiscible rel.prem. curves:

$$
\overline{k_{r}}=f_{I} \cdot k_{r, I}+f_{M} \cdot k_{r, M}
$$

where the weighting functions are normalized such that $f_{I}+f_{M}=1$ and $k_{r, I}$ and $k_{r, M}$ are the relative permeability for immiscible and miscible flow, respectively.

The immiscible weighting function is defined:

$$
f_{I}=\frac{1}{\left(\alpha \cdot N_{c}\right)^{n}+1}
$$

where a and $n$ are two constants to be defined below. 


\section{Definition of capillary number: $N_{c}$}

The capillary number is originally defined as the ratio of viscous forces over capillary forces. Representing these forces by the viscous - and capillary pressure drop in a pore structure, we may write the capillary number $N_{V / P c}=\Delta p_{V} / P_{c}$.

Using Darcy law, we find:

$$
N_{V \mid P_{c}}=\frac{v_{g, \text { pore }} \cdot \mu_{g}}{\sigma_{g o}} \cdot \varepsilon
$$

where $v_{g, p o r e}$ is the gas pore flow velocity and $\mu_{g}$ and $\sigma_{g o}$ are the gas viscosity and gas-oil interfacial tension, respectively. e is quite often assumed to be a constant but is in reality a function of the relative gas permeability; $\varepsilon=\varepsilon\left(k_{r g}\right)$ [20].

In the continuation we define the capillary number for reservoir gas flow:

$$
N_{c g}=\frac{v_{g, p o r e} \cdot \mu_{g}}{\sigma_{g o}}
$$

$\mu_{g}$ and $\sigma_{g o}$ is readily found and presented in the appendix: "PVT analysis results". The pore velocity is defined by the approximation [21]:

$$
v_{g, p o r e}(r, p)=\frac{1}{\phi\left(1-S_{c}\right) \cos ^{2}(\alpha)} \frac{z(p)}{2 \pi r \cdot h} \frac{T_{r e s}}{T_{s c}} \frac{p_{s c}}{p}\left(1+R_{M L G}(p)\right) \cdot q_{g, s c}
$$

Based on Eq. (21) and the data presented in the Figures (b) and (c) in the Appendix, - the capillary number $N_{c g}\left(r=r_{w, p}\right)$ is calculated as shown in Figure 17 .

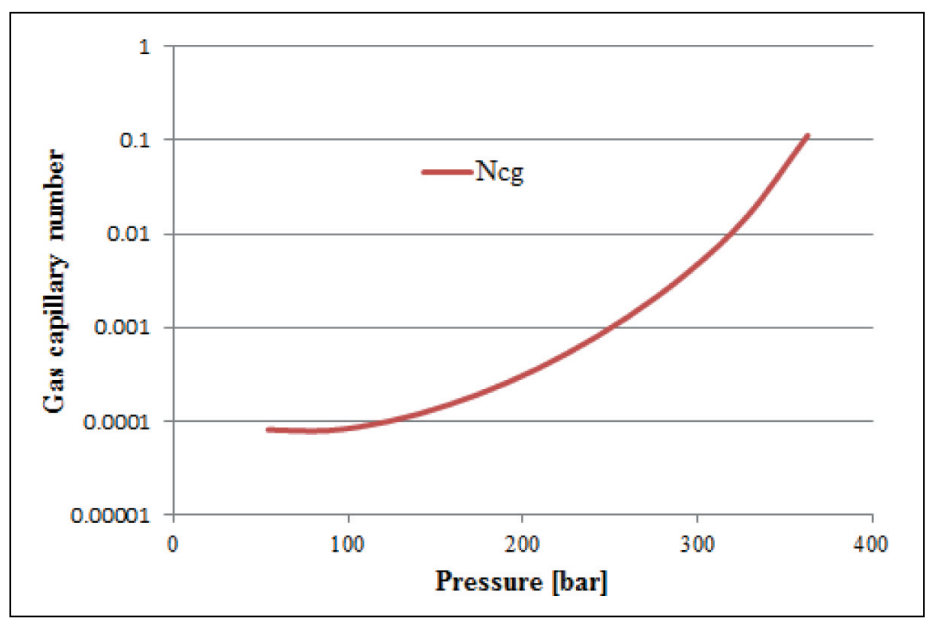

Fig. 17. Capillary number as function of pressure and $r=r_{w}$ 


\section{Linearizing of $N_{c g}$ data}

The immiscible weighting function $f_{I}$ in Eq. (18), can be linearized and we get:

$$
-\ln N_{c g}=\ln \alpha-\frac{1}{n} \ln \frac{1-f_{I}}{f_{I}}
$$

where a and $n$ can be found by plotting $\ln \left(N_{c g}\right)$ as function of $\ln \left(\left(1-f_{I}\right) / f_{I}\right)$. If the weighting function $f_{I} \in<0.01,0.99>$, then $\left(1-f_{I}\right) / f_{I} \in<99,0.01>$.

In order to finalize a plot showing the capillary number as function the weighting function, as in Figure 18, some basic considerations about the flow processes in the reservoir have to be made:

1. capillary forces is dominating flow in the bulk of the reservoir,

2. viscous forces is more important compared to capillary forces in those part where flow velocities are high,

3. in gas condensate flow, interfacial tension between gas and condensate can be very low, reducing the importance of capillary forces.

With the above considerations in mind, we may state that:

$f_{I} \rightarrow 1$ when capillary forces are dominating, associated with low $N_{c g}$ values,

$f_{I} \rightarrow 0$ when viscous forces are dominating, associated with high $N_{c g}$ values.

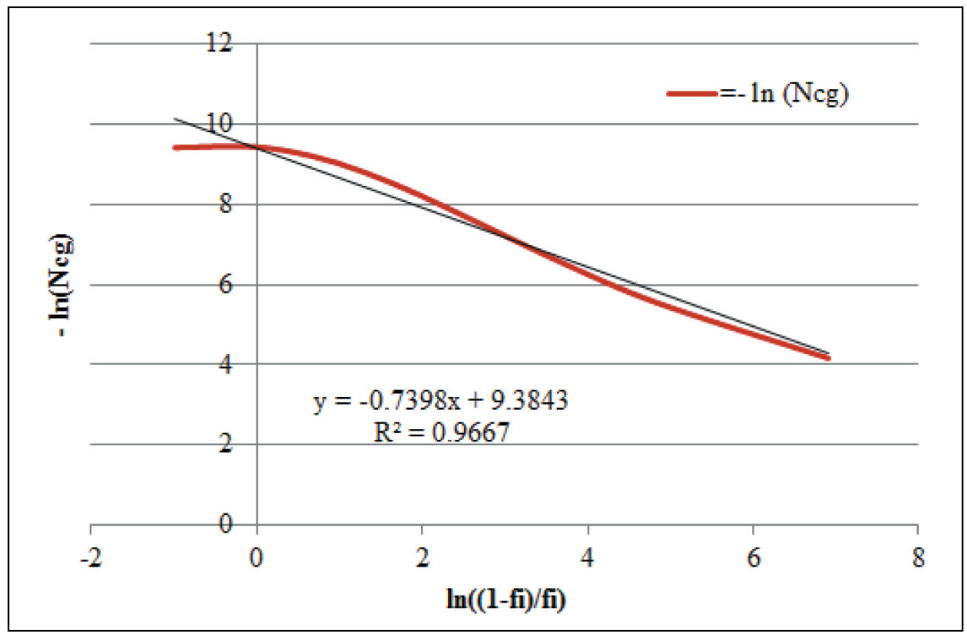

Fig. 18. Linearized $N_{c g}$ data as function of weighting function $f_{I}$, where the weighting function decrease as the power of 3

Using the range of data shown in Figure 17 we find that when $f_{I} \in\langle 1,0\rangle$ then $N_{c g} \in<10^{-4}, 0.1>. N_{c g}$ is a function of pressure while $f_{I}$ is not directly defined as a function of pressure. There is no obvious or direct relationship stating how $f_{I}$ will vary 
when $N_{c g}$ is varying. On the other hand, Eq. (22) states a linear relationship between the variables plotted and $f_{I}$ should decrease when $N_{c g}$ is increasing, as stated above. Various decline rates has been tried; where $f_{I}$ is linearly decreasing, as the square, as the third power and so on. Figure 18 show the linear relation ship in Eq. (22) where $f_{I}$ is decreasing as the third power. The data plotted seems to be quite linear and from the equation of the linear trend one can calculate the constants a and $n$ using Eq. (22). With a and $n$ at hand, an average weighting function $\overline{f_{I}}$ is obtained using Eq. (18) for various values of $N_{c g}$ and an average rel.perm. curve is obtained by Eg. (17).

\section{Average rel.perm. curves for the NS-model}

The average rel.perm. curves in the NS-model is defined as a grand average, first by Eq. (17), where the weighting function $f_{I}$ is averaged over all reservoir pressures; $\overline{f_{I}}$. Table 5 shows the first step in this averaging process, where three different decline rates are used. $f_{I}$ are here declining from 0.99 to 0.01 at different powers related to an increase in $N_{c g}$.

\section{Table 5}

Calculations based on linearized data as presented in Figure 18

\begin{tabular}{|l|c|c|c|}
\cline { 2 - 4 } \multicolumn{1}{c|}{} & 2 & 3 & 4 \\
\hline$n$ & 1.04 & 1.35 & 1.69 \\
\hline$\alpha$ & 7270 & 11900 & 15001 \\
\hline$\overline{f_{I}}$ & 0.330 & 0.230 & 0.168 \\
\hline
\end{tabular}

In the continuation we have chosen a decline rate of power 3 , giving an average weighting function equal to $f_{I}=0.230$, as shown in the Table 5 .

The rel.perm curves $\overline{k_{r o}}$ and $\overline{k_{r g}}$ is plotted in Figure 19 together with the miscible and immiscible rel.perm. curves, from above.

In order to compare the average rel.perm curves in the NS-model with the rel.perm. curves in the LD-model, a re-normalization of the saturation along the x-axis from effective - to oil saturation has to be performed, i.e. $S_{o} \Rightarrow S_{\text {eff. }}$ This re-normalization is using the following relation:

$$
S_{e f f}=\frac{S_{o}-S_{w i}}{1-S_{w i}-S_{g r}}
$$

where $S_{w i}$ and $S_{g r}$ are the initial water saturation and the residual gas saturation, respectively.

Figure 20 shows the rel.perm. curves for the two models. (The broken lines are the average NS-model). 


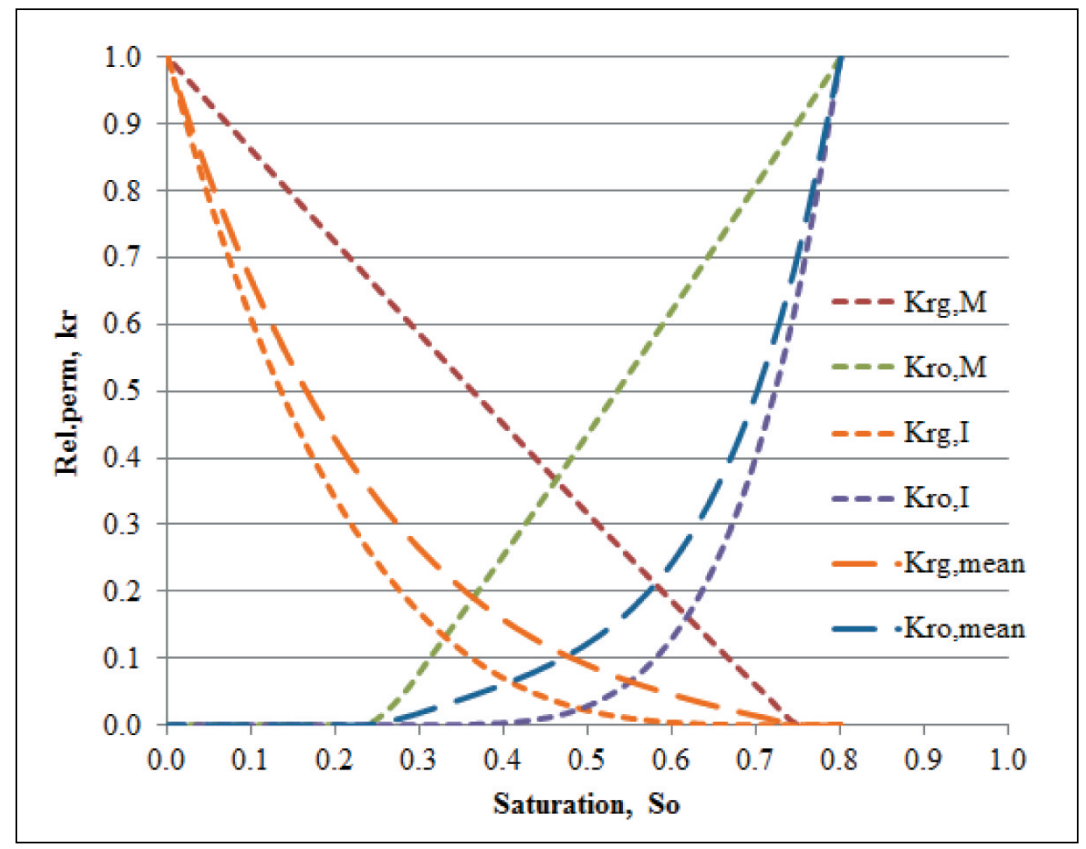

Fig. 19. Miscible, immiscible and average rel.perm. curves for the NS-model

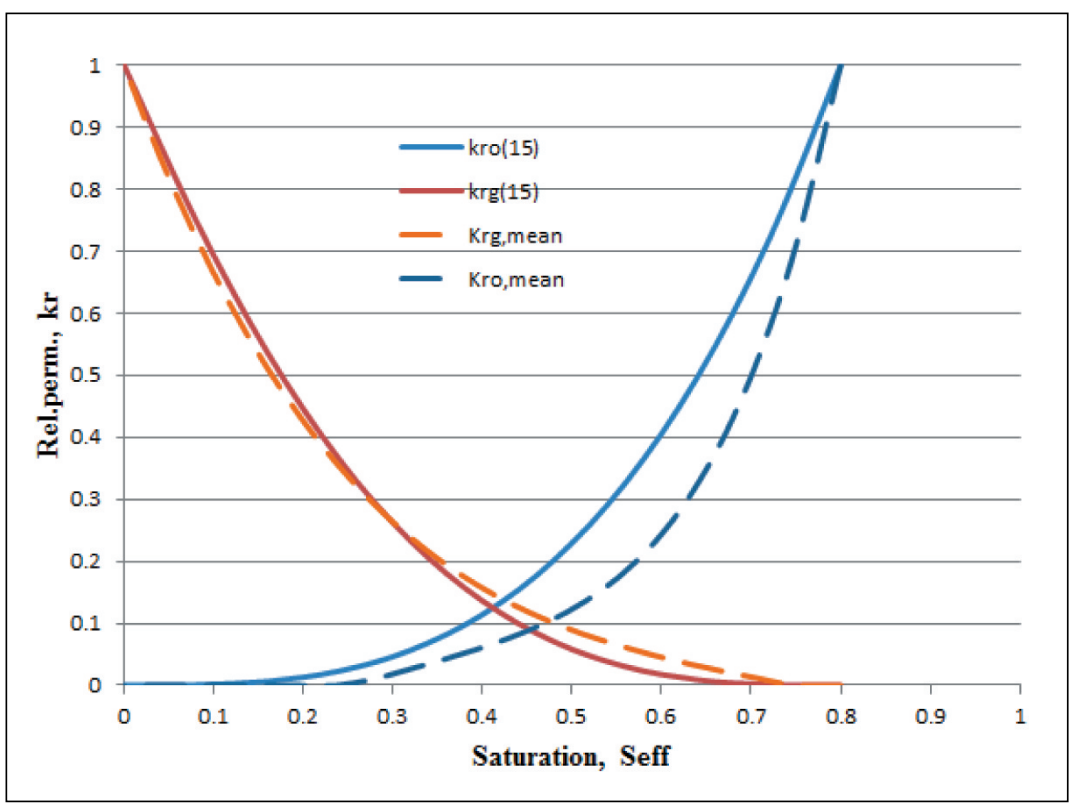

Fig. 20. Rel.prem. curves for the LD- and NS models 
As seen from the Figure 20, the two gas curves seems to be practically identical. This observation is in part confirmed in the gas production plot in Figure 10a, where the gas production profiles are practically overlapping. The oil curves does not overlap so nicely, where $k_{r o}$ for the LD-model is rising more rapidly with saturation than is the case for the NS-model. Consequently, oil production is higher in the LD-model, as can be seen in Figure 10b.

\section{CONCLUSION}

In this article we have modeled gas-condensate banking and reduced well deliverability, using two, in principle, different models. A set of numerical simulations have been performed by the Eclipse simulator on a cylindrical layered reservoir with the well at the center for a rich gas-condensate fluid. The same set of simulations has also been simulated using an analytical model by performing linear dynamical pressure and flow calculations, based on an assumption of how an immovable bank of condensed oil will develop in the reservoir.

In the linear dynamic model, effective permeabilities are calculated based on explicit calculations of a dynamic gas-oil ratio, and does therefore not require reservoir rel.perm. data. The numerical simulations, using Eclipse, where therefore performed using synthetic rel.perm. data for miscible and immiscible flow conditions. The simulations show:

\subsection{General observations}

Flow characterized by miscible and immiscible conditions show very different reservoir behavior with respect to pressure development in the reservoir, where the analytical calculations seems to be more similar to miscible flow than to immiscible flow behavior.

Pressure development:

- The Eclipse simulations show an earlier onset of two phase flow, when $p<p_{\text {dew }}$.

- Onset of two phase flow the analytical model is related to how much oil can be stored in the reservoir before the critical saturation is exceeded.

Productivity index:

- The reservoir productivity vary drastically between the miscible and immiscible flow behavior, where the miscible case is showing a highly productive reservoir while 
in the immiscible case productivity is dropping dramatically when two phase flow commences.

- The productivity generated by the analytical model resembles the immiscible case in form but to a lesser degree in amplitude.

Non-Darcy skin:

- For the non-Darcy skin factor chosen, additional pressure drop is observed in both models.

- In the Eclipse simulations, considerably higher pressure drop is observed in the immis cible case than in the miscible case.

- In the analytical model, the increased pressure drop were so deep that it triggered onset of minimum bottom hole pressure control, which led to reduced flow rate and delayed production.

Average permeability:

- Average rel.perm. data is generated for the Eclipse simulations, where the weighting functions are based on the capillary number. A linearized plotting technique is used when generating these weighting functions.

- The average rel.perm curves generated on basis of the miscible and immiscible curves is matching the analytical rel.perm.data for gas surprisingly well, while the average rel.perm. oil curve generate less oil condensate production than the analytical model.

\subsection{Future work}

The saturation of immobile oil $S_{o}(r, t)$, defined by Eq. (10), and depicted by Figure 4 and Figure 5, is introduced into the model "by hand", i.e. it represents an idea of how such a saturation might look like.

A successful modeling of $S_{o}(r, t)$ should depend on detailed appreciation and understanding of effects of thermodynamical fluid phase behavior in combination with the interplay of various forces; viscosity, capillary, gravitational and inertial acting on fluid flow in time and space.

\section{Acknowledgement}

A special thanks to Iman Shahim for performing the Eclipse simulations as part of his student project at the University of Stavanger. 


\section{APPENDIX A: PVT ANALYSIS RESULTS}

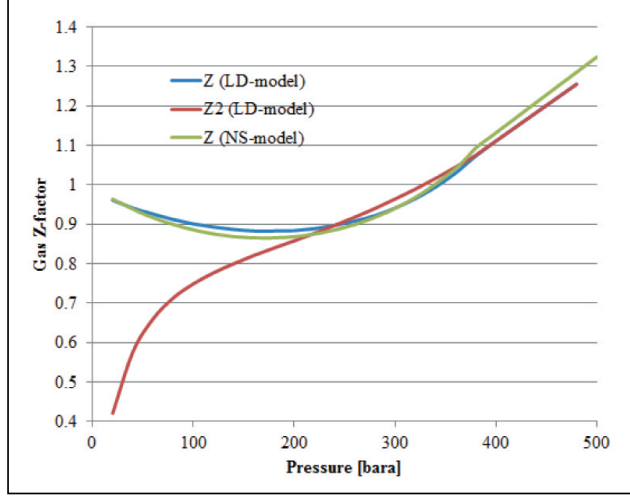

(a) Vapor Z-factor

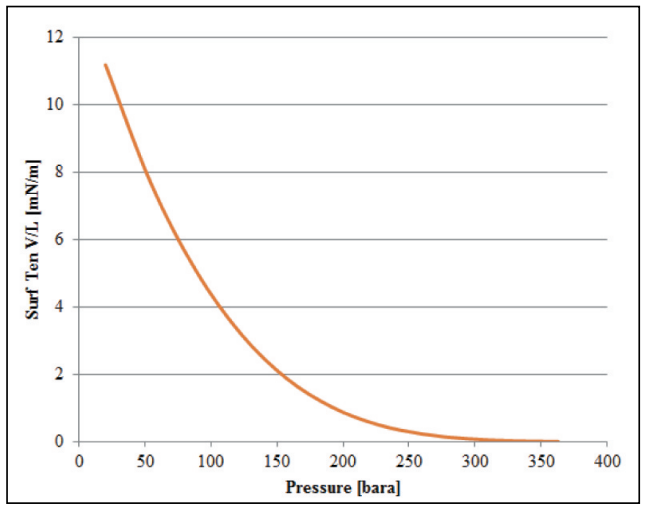

(c) Vapor-liquid interfacial tension; $\sigma_{o g}$

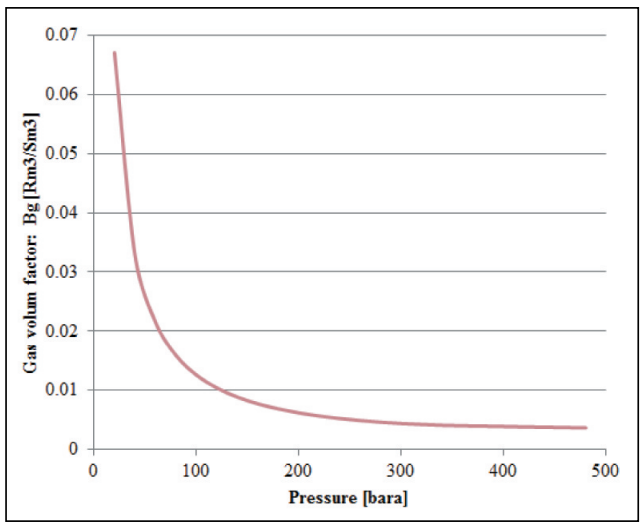

(e) Gas volume factor; $B_{g}$

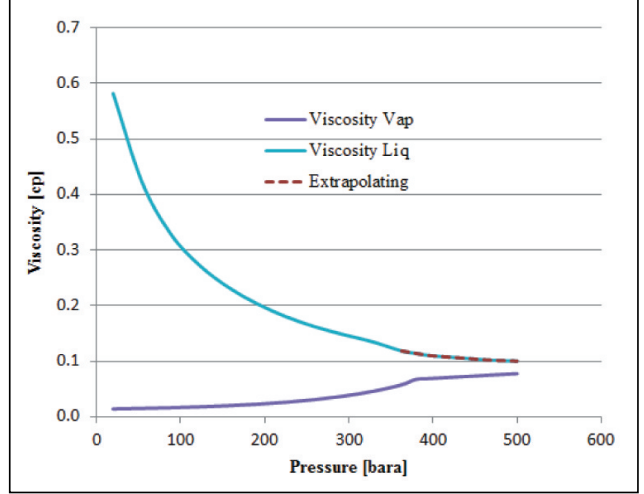

(b) Vapor and liquid viscosities; $\mu_{g}, \mu_{o}$

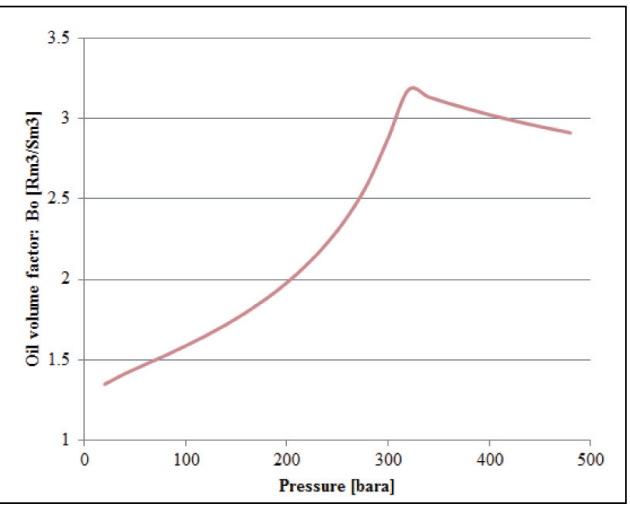

(d) Oil volume factor; $B_{o}$

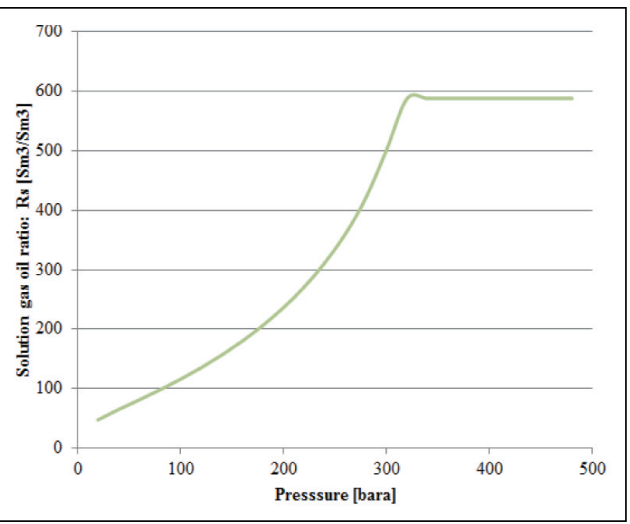

(f) Solution gas-oil ratio; $R_{s}$ 


\section{NOMENCLATURE}

$B_{o}, B_{g}-$ Volume factors for oil and gas $\left[\mathrm{Rm}^{3} / \mathrm{Sm}^{3}\right]$

$c, c_{w}, c_{r}-$ Compressibility, Water compressibility, Reservoir (formation)

$D$ - Non-Darcy factor [1]

$G_{p}, G_{\dot{v}} G_{L p}, G_{L i}-$ Gas production, Initial Gas volume, Liquid Production, Initial liquid volume $\left[\mathrm{Sm}^{3}\right]$

$h$ - Reservoir height $[\mathrm{m}]$

$k, k_{g}, k_{o}$ - Absolute permeability, Effective gas and oil permeability [D]

$k_{r g}, k_{r o}$ - Relative gas and oil permeability [1]

$L 1, L 2$ - Oil saturation shape factors [1]

$m, \bar{m}, m_{b h}$ - Pseudo pressure, Mean pseudo pressure, Bottom hole pseudo pressure [bar]

$p, p_{i}, p_{g}, p_{o}, p_{r}-$ Pressure, Initial pressure, Gas pressure, Oil pressure, Reference pressure [bar]

$q_{s c}$ - Surface gas flow rate [ $\mathrm{Sm}^{3} /$ day]

$R_{p}, R_{s}, r_{s}$ - Production GOR, Solution volume factors for oil and gas $\left[\mathrm{Sm}^{3} / \mathrm{Sm}^{3}\right]$

$r_{w}, r_{e}, r_{c o}, r_{d e w}-$ Well radius, Reservoir boundary radius, Radius dividing Region 1 and 2, Radius dividing Region 2 and 3 [m]

$S, S_{n D}$ - Mechanical skin, Non-Darcy skin [1]

$S_{o}(r ; t)$ - Oil saturation profile [1]

$S_{o}, S_{c o}-$ Oil saturation, Critical oil saturation [1]

$S_{w}-$ Water saturation [1]

$T, T_{i}, T_{n}$ - Temperature, Reservoir temperature, Standard temperature $(288 \mathrm{~K}) ;[\mathrm{K}]$ compressibility [1/bar]

$v$ - Flow velocity $[\mathrm{cm} / \mathrm{s}]$

$V_{g g n}, V_{o o n}, V_{\text {ogn }}, V_{\text {gon }}-$ Gas from gas, Oil from oil, Oil from gas, Gas from oil [ $\left.\mathrm{Sm}^{3}\right]$

$\Delta V_{o}, V_{o}, V_{c o}$ - Oil produced, Condensed oil, Irreducible oil $\left[\mathrm{Rm}^{3}\right]$

$V_{p}, V_{g}, V_{o}, V_{H C}$ - Pore volume, Gas Volume, Oil volume, Hydrocarbon volume $\left[\mathrm{Rm}^{3}\right]$

$Z_{i}, Z_{2}, Z_{2 i}-$ Gas compressible factor, Two-phase factor, Initial factor [1]

$z$ - Reservoir depth [m] 


\section{GREEK SYMBOLS}

$$
\begin{aligned}
\alpha & - \text { Constant [1] } \\
\phi & - \text { Reservoir porosity [1] } \\
\lambda- & \text { Pore size distribution index [1] } \\
\mu, \mu_{g}, \mu_{o}- & \text { Viscosity, Gas viscosity, Oil viscosity [cp] } \\
\rho, \rho_{g}, \rho_{o}, \rho_{g n}, \rho_{o n}-\text { Density, Gas and oil density, Gas and oil density at normal } & \text { condition }\left[\mathrm{g} / \mathrm{m}^{3}\right] \\
\sigma_{o g}- & \text { Interfacial tension between oil and gas }[\mathrm{mPa} \cdot \mathrm{s}]
\end{aligned}
$$

\section{REFERENCES}

[1] Dake L.: The Practice of Reservoir Engineering. Developments in Petroleum Science, 36. Elsevier, 1994.

[2] Danesh A.: PVT and Phase Behavior of Petroleum Reservoir Fluids. Elsevier, 1998. ISBN 0-44-82196-1.

[3] Afidick D., Kaczorowski N., Bette S.: Production performance of a retrograde gas reservoir: $A$ case study of the Arun Field. SPE-28749-MS. In: SPE Asia Pacific Oil and Gas Conference, Melbourne, Australia, 7-10 November 1994.

[4] Hinchman S., Barree R.: Productivity loss in gas condensate reservoirs. SPE 14203. In: SPE Annual Technical Conference and Exhibition, Las Vegas, NV, 1985.

[5] Vo D., Jones J., Raghavan R.: Performance prediction for gas condensate reservoirs. SPE Formation Eualuation, 1989.

[6] Barnum R., Brinkman F., Richardson T.: Gas condensate reservoir behaviour: Productivity and recovery reduction due to condensation. SPE-30767-MS. In: SPE Annual Technical Conference and Exhibition, Dallas, Texas, 22-25 October 1995.

[7] Whitson C., Kuntadi A.: Khuff gas condensate development. IPTC 10692. In: International Petroleum Technology Conference, Doha, Qatar,2005.

[8] Allen F., Roe R.: Performance characteristics of a volumetric condensate reservoir. Petroleum Transactions. AIME, 1950.

[9] Abel W., Jackson R., Wattenbarger R.: Simulation of a partial pressure maintenance gas cycling project with a compositional model, Carson Creek Field, Alberta. JPT, 1970.

[10] Fevang Ø., Whitson C.: Modeling gas-condensate well deliverability. SPE Reservoir Engineering, 1996.

[11] Narayanaswamy G., Pope, G., Sharma, M.: Predicting gas condensate well productivity using capillary number and non-Darcy effects. SPE-51910-MS. In: SPE Reservoir Simulation Symposium, Houston, Texas, 1999.

[12] Narayanaswamy G., Sharma M., Pope G.: Effect of heterogeneity on the non-Darcy flow coefficient. SPE Res Eval \& Eng., SPE-56881-PA,1999. 
[13] Coles M., Hartman K.: Non-Darcy measurements in dry core and the effect of immobile liquid. SPE-39977-MS. In: SPE Gas Technology Symposium, Calgary, Alberta, 1998.

[14] Kumar R.: Productivity improvement in gas condensate reservoirs through fracturing. M.Sc. thesis, University of Texas, Austin 2000.

[15] Ursin J.: Linear dynamics of gas condensate well deliverability. Transport in Porous Media, vol. 70, 2007, pp. 375-406.

[16] Lee A., Gonzales M., Eakin B.: The viscosity of natural gases. Gas Technology, SPE Preprint Series, 1(13), 1977.

[17] Whitson C., Brule M.: Phase Behauior. SPE Monograph Series. Society of Petroleum Engineers Inc., 2000.

[18] Brooks R., Corey A.: Hydraulic properties of porous media. Colorado State University, Fort Collins, Colorado, 1964.

[19] Blom S., Hagoort J.: How to include the capillary number in gas condensate relative permeability functions? SPE 49268. In: 1998 SPE Annual Technical Conference and Exhibition held in New Orleans, Louisiana, 27-30 September 1998.

[20] Whitson C., Fevang, O., Saevareide A.: Gas condensate relative permeabilty for well claculations. SPE 56476. Presented at the 1999 Annual Technical Conference and Exhibition held in Houston, Texas, 3-6 October, 1999.

[21] Ursin J.: Fluid flow in gas condensate reservoirs: the interplay of forces and their relative strengths. Journal of Petroleum Science \& Engineering, 41, 2004, pp. 253-267. 